\title{
La Génesis Literaria en Francisco Rojas González
}

D ARA valorar la obra del autor jalisciense Francisco Rojas González, es P imprescindible verla en relación con su circunstancia: México entre r 920 y I95 I, país en proceso de cambios dramáticos y revolucionarios. Nuestro propósito aquí es examinar el entronque de esta obra de ficción por la realidad de la cual el autor escogía la materia prima que transformaba en literatura.

Al entrar el joven burócrata en el servicio diplomático en $\mathbf{1 9 2 0 , \text { su }}$ punto de vista se caracteriza por un provincialismo marcado. La vida intelectual de Rojas González, desde aquellos años hasta su muerte en I95I, es trayectoria constante de amplificación, hacia una perspectiva verdaderamente nacional. El Rojas González maduro se preocupa profundamente por la Revolución Mexicana, en tiempo y espacio: pinta sus etapas históricas, busca sus efectos en vidas humanas de todas las disímbolas regiones geográficas de la nación. Dedica atención especial a los valores indígenas - valores tradicionales y actuales-y al problema de integrarlos en la escena contemporánea.

En términos literarios, se puede medir la trayectoria creadora del autor a partir de su primer cuento publicado, "El último charro", de 1928,1 hasta la colección póstuma de $195^{2}$, El diosero. ${ }^{2}$ Aquél-cuento poco conocido- no interesa por su virtud artística, sino porque equipara mexicanidad y provincialismo. Lo mexicano puro mora en las costumbres de la patria chica. Esta, momento cumbre de Rojas González cuentista, sintetiza arte narrativa y sentido humanista. Debajo de la estructura artística de la obra literaria como producto de la intuición del autor, se

1 Francisco Rojas González, "El último charro", Revista de Revistas (México, XVIII, 926 (5 de feb., 1928), pp. 15, 47, 48, 49.

2 Francisco Rojas González, El diosero, México: Fondo de Cultura Económica, 1952. 
percibe un fondo de experiencia vital y personal. El diosero y la colección precedente, Cuentos de Ayer y de Hoy (1946), ${ }^{3}$ revelan temas que trascienden lo regional, que penetran en la actitud mexicana ante la religión, la angustia de morir, la angustia de vivir. Por medio de temas nacionales iba acercándose a conceptos universales.

El fondo humano en la obra de este escritor está emparentado con su vida activa y multifacética en el medio mexicano. Los componentes de esta vida incluyen varios años de estudios etnológicos con Andrés Molina Enríquez y Miguel Othón de Mendizábal, viajes a todos los rincones de México en plan de investigador del Instituto de Investigaciones Sociales, participación en el Bloque de Obreros Intelectuales, apoyo activo a la campaña política de don Adolfo Ruiz Cortines. En I95r, cuando la muette le cortó la vida súbitamente a los cuarenta y ocho años, ya tenía planeada su tercera novela. Con título $L a$ tierra es de nadie, pensaba trazar la miseria personal de un grupo de campesinos imposibilitados en su esfuerzo por cultivar parcelas inadecuadas, empujados algunos hacia la pobreza metropolitana, otros a la explotación bracera. Otra vez se proponía novelar a base de la vida circundante, el drama mexicano de su época.

Vínculos estrechos unen el mundo literario de Rojas González con el mundo real de la sociedad actual. Sin embargo, las dos novelas y los cincuenta y cinco cuentos dejados por él son poblados por un espectro de personajes mexicanos, dotados de individualidad y de propia existencia literaria. En la creación de personajes y situaciones, el autor recurrió con frecuencia a la experiencia teal, prefiriendo basarse en la vida misma como fuente de inspiración, para entonces transformar según su intuición literaria. Resulta posible destacar cinco tipos concretos de materia preexistente empleados por Rojas González como puntos de arranque en su proceso creador.

El primer tipo es la observación directa, de la cual el cuento "La plaza de Xoxccotla" (El diosero) proporciona un ejemplo ilustrativo. EJ autor de este artículo visitó el pueblo de Xoxocotla, en el Estado de Morelos, y conversó con el jefe político, el señor Fiacro Lugo. La plática rindió informes significativos acerca de los principios del cuento de Rojas González.

La plaza de Xoxocotla, importante en el relato, corresponde de hecho a su representación literaria, según las palabras del narrador, don

3 Francisco Rojas González, Cuentos de Ayer y de Hoy, México: Editorial Arte de América, 1946. 
Eleuterio: "una plaza con sus banquetas, sus prados y su tiosco rodiado de faroles..." La población vecina, como en el cuento, es Puente de Ixtla. De más interés, no obstante, es el hecho de que el fondo histórico de Xoxocotla, del cual depende la fuerza motriz de la trama, es asimismo verídico. El señor Lugo confirmó que Lázaro Cárdenas, de candidato a la presidencia, había visitado el pueblo y había prometido pavimentar la plaza, proveer agua por tuber'as y construir una escuela - promesas que, como en el cuento, fueron realizadas. Hoy en día, una escuela pública, substanciosa y bien mantenida, ocupa lugar prominente en la plaza, cerca de la imponente iglesia colonial. En el frente aparece su nombre en lengua náhuatl, Tlamacbteloyan," y debajo de este título la inscripción: "Escuela Primaria Rural Federal, Gral. Lázaro Cárdenas". La conversación con el señor Lugo confirmó además que Rojas González había captado en su cuento la veneración que sentían los ciudadanos por Cárdenas, el presidente que había cumplido sus promesas a una remota comunidad semiindígena.

Pero es de igual importancia que no había existido un tal don Eleuterio Ríos, y que el señor Lugo no conocía a nadie que hubiera hecho un papel central análogo al del protagonista del cuento. En la creación de este personaje, en la estructuración de los acontecimientos que inducen suspenso y clímax, en el estilo y lenguaje están las claves de la transformación artística realizada por el autor, partiendo de la realidad de Xoxocotla.

La señora Lilia Lozano viuda de Rojas González, ha citado otro cuento inspirado en la realidad observada. Señalando una reproducción de la Mona Lisa que todavía adorna la sala de su casa, ella explicó que hace algunos años una sirvienta indígena de la familia pidió permiso de colocar una ofrenda de flores y velas ante "la virgencita". Este incidente de la vida real, trasplantado al ambiente de una comunidad indígena, formó la base de la trama de "Nuestra Señora de Nequetejé" (El diose-: ro). El cuento imaginativo se sirve del incidente como mecanismo anect dótico, pero se lo enfoca según la psicología y la religiosidad de los indios pames, y según la incapacidad de un psicólogo moderno de penetrar en la mente indígena mediante fríos datos estadísticos.

Una vivencia real, según la señora Lozano de Rojas, dio forma al esquema del relato "Silencio en las sombras" (Cuentos de Ayer y de Hoy). Los valores del cuento residen en la contemplación abstracta de la belleza y en el problema de comunicar la emoción del amor. No obs-

4 Significado: "el acto de enseñar". 
tante, el origen concreto del cuento está relacionado con un matrimonio que la señora de Rojas había observado durante su niñez en Guadalajara. Su descripción de los esposos, uno ciego y la otra sordomuda, motivó en Rojas González el estudio literario de los problemas vividos por tal pareja.

La segunda fuente de materia prima para su literatura tuvo su origen en los estudios antropológicos del autor. Durante casi veinte años Rojas González colaboró como investigador del Instituto de Investigaciones Sociales de la Universidad Nacional Autónoma de México. Un caso de los vínculos entre literatura y antropología se encuentra en un artículo erudito de Rojas González, "Totemismo y nahualismo", publicado en la Revista Mexicana de Sociología en I944. Comienza repasando la tradición totémica en las religiones primitivas, y su parentesco con La serie de creencias religiosas que circundan la figura del nahual en México. Refiriéndose a autoridades internacionales (Reinach, Freud, Linton) y a cronistas de México (Sahagún, Landa, Núñez de la Vega), demuestra el autor los puntos de contacto entre totemismo - la asociación colectiva que tiene un grupo emparentado con un animal-y nahualismo - la creencia en las cualidades protectoras que el espíritu de un animal proporciona al individuo:

El "nahualismo", también depósito imaginario de fuerza, santidad y destreza, parte del resultado de una experiencia que es fruto a su vez del conocimiento: el "tonalamatl", de cuyas anotaciones los acólitos del culto señalaban a cada quien una bestia o ave protectora, con cuya vida quedaba siempre ligada la existencia del hombre.5

Prosigue el artículo explicando que del tonalamatl, libro sagrado, escogieron los sacerdotes prehispánicos el nahual de cada individuo. Comenta el concepto. antropológico a base del cual más tarde el autor ideó uno de sus cuentos magistrales:

De allí precisamente viene el nombre de "tona" con que los indios del sur de México suelen designar, aún en nuestros días, la bestia, alimaña o ave que les sirve de "alter ego". 6

5 Francisco Rojas González, "Totemismo y nahualismo", Revista Mexicana de Sociologia, VI, 3 (1944), p. 367.

6 Ibid., p. 364. 
El cuento "La tona" (El diosero), depende de esta tradición indígena en su trama y en la psicología de su protagonista. El desenlace simboliza el mestizaje entre tradiciones antiguas y técnica moderna, con la resolución de Simón, el indio zoque, de darle a su niño el nombre de "Bicicleta". Simón había regado ceniza alrededor de la choza, para nombrar "tona" del niño al primer animal que dejara huella en la ceniza. La huella que encontró el indio fue la del vehículo del médico. El elemento antropológico, empleado por Rojas González el cuentista, tiñe el cuento de verdad humana.

Otra historia estrechamente vinculada con las investigaciones antropológicas del autor es "Hículi Hualula" (El diosero). En diciembre del año pasado, al conmemorar el décimo aniversario del fallecimiento de Rojas González, el Dr. Lucio Mendieta y Núñez se refirió a uno de los mejores estudios científicos del fallecido investigador: "El jículi ba-ba o estudio etnográfico sobre el peyote". Trata del uso ritual entre varios grupos indigenas de una especie de cacto, respetado por ellos por tener poderes sobrenaturales. Citó el Dr. Mendieta y Núñez a los huicholes, resumiendo los comentarios de Rojas González acerca de ellos:

Los huicholes llaman "venado" al jículi y le atribuyen cualidades divinas; cura las enfermedades, da salud y larga vida. Cuando los indios tarahumaras y huicholes comen el peyote, sienten que calma la sed y la fatiga, y tomándolo en fuertes cantidades, les produce alucinaciones, estados de euforia y alegría.?

Resulta evidente que al desarrollar esta monografía, Rojas Gonzáles concibió el cuento "Hículi Hualula", cuya trama se concentra en las investigaciones desafortunadas de un antropólogo entre los huicholes. Termina el cuento con una nota de fantasía y sátira, pues el investigador imprudente, tras demostrar carencia completa de sensibilidad frente a las creencias y tradiciones indias, se encuentra, al volver a la metrópoli, bajo el dominio extraño de un poder desconocido. Esta fuerza mágica le empuja implacablemente hacia las alucinaciones y la locura.

Los fundamentos de la obra literaria de Rojas González se encuentran no solamente en observaciones directas y conocimientos científicos, sino también-ocurrencia común en el mundo literario-en ideas ya . sugeridas por otros autores.

7 Lucio Mendieta y Núñez, "Francisco Rojas González, etnógrafo", El Universal, México, 21 de enero, 1962, p. 2. 
De vez en cuando, se perciben en los cuentos de este autor no sólo influjos de escritores contemporáneos, sino préstamos directos. Tal es el caso del cuento "El mendigo", por Octavio Rivera. Este breve relato apareció en el Universal Ilustrado en julio de 1932. Sentimental de tono, fundada la trama en anécdota pura y llamamiento obvio a las emociones, el cuento demuestra un lenguaje crudo, atestado de los clichés del naturalismo. Pero la conclusión, que contiene la única chispa de interés del cuento, debe haber atraído a Rojas González. Años después, él creó un cuento enteramente distinto literariamente, pero empleando con eficacia esta misma conclusión en su clímax. Este cuento, "Una cáscara en la banqueta", obra con méritos estilísticos, penetra en la psicología de un hombre a punto de morirse de hambre. Es una denuncia amarga de la indiferencia metropolitana ante el sufrimiento de los pobres, y la conclusión súbita e inesperada cobra fuerza adicional empleando a un niño como espejo de la apatía y del egoísmo de los adultos. Escrito por Rojas González unos trece años después del cuento de Octavio Rivera, "Una cáscara en la banqueta" vio la luz en Letras de México en I945, y más tarde en la colección Cuentos de Ayer y de Hoy. En 1958 el crítico chileno Ricardo Latcham lo seleccionó como uno de los cinco cuentos mexicanos en su Antología del cuento bispanoamericano.

El que Rojas González haya tomado prestado de Rivera un elemento de su historia queda inconfundible. Los incidentes que finalizan ambos cuentos se aparean perfectamente. Es más: en 1932 los cuentos de Rojas González iban apareciendo en el Universal Ilustrado. Dos relatos suyos se publicaron en esta revista un mes antes de que apareciera "El mendigo", y otro al mes siguiente. Es lógico, por lo tanto, dar por supuesto que Rojas González leía la revista con regularidad en aquella época.

Otros ejemplos que se pueden citar tocante a las concepciones originales de temas o personajes en la obra de Rojas González se clasifican más bien como sugerencias o influjos que como préstamos. El personaje secundario Pérez Gómez, en La negra Angustias, 8 demuestra una personalidad ya familiar para el lector. Joven "intelectual" de la clase media de la capital, versado en la literatura exótica del radicalismo europeo, se revela, al confrontar la actual lucha revolucionaria, oportunista egocéntrico-dispuesto para aliarse con el grupo que lleva la ventaja. Su antecedente literario más evidente es Luis Cervantes en Los de abajo, 1944.

8 Francisco Rojas González, La negra Angustias, México: E.D.I.A.P.S.A., 
quien comparte iguales características. Feto se le puede atribuir asimismo a Pérez Gómez un parentesco más remoto con un personaje semejante en Fuertes y débiles, de López Portillo y Rojas, el tío de Francisco Rojas González. El maestro semieducado de esta novela, don Severiano Alcocer, pretende hacerse caudillo de los campesinos que se lanzan a la Revolución. La descripción del autor descubre un personaje de linaje parecido al de Pérez Gómez:

. . pertenecía al soberbio grupo de los espiritus superiores, no comprendidos y víctimas de las injusticias sociales... había acabado por creerse un sabio hecho y derecho, superior a la turbamulta... y tomando por lo serio la ditirámbica fraseología de los escritores y poctas. . . creíase de buena fe solemne mistagogo. . apóstol inmortal. . que dirigía la marcha del pueblo hacia una tierra prometida. ${ }^{9}$

Como muchos escritores que buscaban subrayar las peculiaridades de la herencia cultural de México, Rojas González a veces se valió de los libros de historia. La trama de su novela Lola Casanova tiene como punto de arranque una leyenda citada en el tomo histórico del Dr. Fortunato Hernández. ${ }^{11}$ Otro ejemplo lo constituye un cuento inédito $\mathrm{e}$ incompleto, encontrado entre los papeles del fallecido autor. El cuento de- , muestra el propósito de dramatizar un incidente de la vida de don Venustiano Carranza.

La concepción histórica es fundamental en varios de los cuentos cuyo fondo es la Revolución Mexicana en sus múltiples etapas. El ambiente de "El caso de Pancho Planas" (El pajareador) es el período de lucha fratricida y sangrienta, mientras que relatos como "Voy a cantar un corrido" (Sed), se sitúan históticamente en los años de la rebelión cristera.

El último tipo de materia preexistente empleada por este autor fue su propia literatura. Por ejemplo, el cuento "Lancaster Kid" (El pajareador) incluye varios elementos constitutivos del primer relato de Rojas González, escrito en i928. La primera mitad de "Lancaster Kid" se refiere a la inminente carrera en la cual participarán un aristocrático caballo de cría importado desde Halifax y un humilde "cuaco" criado en

9 José López Portillo y Rojas, Fuertes y débiles, México: Librería Española, sin fecha, p. 216.

10 Francisco Rojas González, Lola Casanova, México: E.D.I.A.P.S.A., 1947.

11 Fortunato Hernández, Las razas indigenas de Sonora y la gaserra del Yaqui, México: Casa Editarial J. de Elizaldi, 1902. 
Jalisco. La carrera se lleva a cabo durante la fiesta de Ia Virgen de Guadalupe, el doce de diciembre, en medio de una atmósfera de carnaval y celebración. Todos estos elementos de trama habían formado parte, asimismo, de "El último charro", aunque desde el punto de vista literario, el cuento posterior supera completamente a éste. Cabe mencionar que, al terminar la carrera de caballos, las dos tramas viran en direcciones distintas.

Con respecto a esta fuente de inspiración, vale la pena examinar la paternidad literaria de la protagonista de La negra Angustias, cuestión sobre la cual ya han comentado varios críticos y autoridades. La maestra Mary Ann Lowe, en su tesis sobre las novelas de Rojas González, ${ }^{12}$ se refiere a una entrevista que Fernando Benítez sostuvo con el autor. Este afirmó que en la vida real había conocido a una mujer que le proporcionó la concepción de su personaje novelesco. Según la entrevista, declaró el autor: "... se llamaba Remedios Farrera y fue una de las que empuñó el 30-30 defendiendo las ideas libertarias" ${ }^{13}$ Después de la muerte de Rojas González, su viuda en un artículo de revista subrayó la relación entre Angustias Farrera de la novela y Remedios Farrera, de la Revolución Mexicana real: "El conoció personalmente a la heroína de su libro. La conoció aquí, vieja, muy lejos de la gloria y las hazañas. .."'14

Otra teoría menos convincente y menos substanciosa es la que propone Julia Hernández:

...su Negra Angustias no pasa de ser una adaptación, poco afortunada, de La Fierecilla Domada, de Shakespeare. Aun cuando tenga en ella aciertos tan grandes, como la escena de un burdel. ${ }^{15}$

La negra Angustias no tiene en común con La fierecilla domada nada de significante. La fiereza de Catarina carece totalmente de la masculinidad de Angustias. Tampoco actúa Catarina de jefe. Esta es domada por un Petruchio que la supera en vivacidad, en audacia y en la habilidad de dominar a otros. Por medio del poder imprevisto que ejerce Petru-

12 Mary Ann Lowe, Francisco Rojas Gonzallez, novelista, México: Unión Gráfica, 1957.

13 Fernando Benítez, "Francisco Rojas González, primer premio nacional de literatura", El Nacional, México, 15 de oct., 1944, p. 3.

14 Alberto Pulido Silva, "En el recuerdo de Lilia", Presentamos (México), n. 4 (nov., 1952), p. 16.

15 Julia Hernández, Novelistas y cuentistas de la Revolución, México: Unidad Mexicana de Escritores, 1960, p. 77. 
chio sobre su casa, sus criados, y los que le rodean, logra intimidar a Catarina hasta la sumisión - meta que él esperaba alcanzar desde el momento del casamiento. Por último, no se perciben en Catarina los cambios transitivos que demuestra Angustias. De allí que la analogía de la. señorita Hernández sea "poco afortunada".

Una tercera aseveración proviene del profesor Seymour Menton, de la Universidad de Kansas. El título de su estudio indica la dirección de sus ideas: "La negra Angustias, una Doña Bárbara mexicana". El profesor Menton afirma con claridad que la novela mexicana posee sus propios méritos, pero que:

Rojas González se dejó influir por Gallegos en sus descripciones: de los orígenes, las causas de rebeldía, el dominio sobre los hombres, la derrota por el hombre culto y la vuelta a la nada de la protagonista. 16

De las cinco observaciones del profesor Menton, las primeras dos son acertadas, por lo que atañe a las semejanzas entre las etapas tempranas en las vidas de los dos personajes femeninos, y entre los motivos que las impulsan hacia la rebeldía social. En el caso de doña Bárbara, sin embargo, el poder sobre los hombres constituye un recurso para enriquecerse, mientras que Angustias ejerce sus poderes de jefe acaudillando su banda en escaramuzas revolucionarias. Doña Bárbara se sirve de su encanto personal, de trucos legales, de soborno, y hasta de brujería. El mando de Angustias depende de su vigor innato, de su brutalidad, de la osadía que ella hereda de su padre, y de la simpatía que siente por "los probes". Ambas protagonistas demuestran el poder sobre los hombres, como indica el estudio, pero en metas y en recursos, la naturaleza del poder difiere de manera significativa.

Angustias y doña Bárbara sufren la derrota, como señala el profesor Menton, por hombres de educación superior. Pero la victoria de Santos Luzardo representa el triunfo de lo moral por encima de lo inmoral, de la civilización sobre la barbarie. La derrota de Agustias a manos de Manuel, en cambio, lleva un irónico significado doble - triunfo del hombre parásito y retorno de la protagonista a la femineidad.

Cuando al final de la novela desaparece doña Bárbara, es una vuelta casi total a "la nada". Las circunstancias finales de Angustias, si bien

16 Seymour Menton, "La negra Angustias, una Doña Bárbara mexicana", Revista Iberoamericana, XIX, 38 (abr.-sept., 1944), p. 299. 
distan mucho de idílicas, no obstante son distintas. Ella se ve casada, dispuesta a soportar la indiferencia desdeñosa de su esposo, y feliz con su niño y sus tareas domésticas. En términos humanos esta condición constituye una rebaja considerable, comparada con los días anteriores de poder y de gloria, pero difiere igualmente de "la nada" en la cual se desvanece el personaje central de Gallegos.

La pesquisa de los orígenes literarios del personaje Angustias debe tomar en cuenta otra fuente importante, hasta la fecha ignorada por los críticos. En junio de 1932 , en el Universal Ilustrado, Rojas González publicó un cuento intitulado "Ella". Precediendo a La negra Angustias por unos doce años, la trama de este cuento contiene en miniatura una completa vista previa de la trayectoria emocional de Angustias. El personaje clave de "Ella" es una mujer tosca y agresiva, del tipo "marimacho", que trabaja de capataz en una fábrica. Se enamora de un individuo débil, maestro de escuela, y al casarse con él pierde su actitud característica de agresión. El maestro la domina y la maltrata. Pero hay más, aparte de estas semejanzas generales de personajes y de trama: varios acontecimientos específicos y rasgos personales de "Ella" corresponden con precisión a los de La negra Angustias. La descripción siguiente, tomada del cuento: "Maldecía, bebía y fumaba como el más empedernido de los capataces", se aplica con igual exactitud a Angustias en la memorable escena de la cantina. En las dos obras, las mujeres limpian el salón de clase y traen flores con anticipación a la llegada del maestro. De la misma manera, se enfurecen ambas protagonistas cuando, en gesto de desprecio, hombres groseros colocan un clavo en la silla del maestro afeminado. Los dos personajes centrales aprenden a deletrear "amor", y las dos llegan a clase exhalando olor de aguardiente. En ambos casos el marido acaba de vivir del sueldo que recibe la esposa.

Parece evidente que la novela posterior empleó y amplificó la trama apenas esbozada en el cuento de r932, otorgándole un ambiente distinto.

No existe razón para negar la afirmación del autor mismo de que la inspiración de La negra Angustias provino, en parte, de una persona que él había conocido. Este tipo de discusión ha ocurrido asimismo con relación a la génesis de Don Segundo Sombra y Doña Bärbara. Además, las observaciones del profesor Menton acerca de la importancia de la novela de Rómulo Gallegos ayudan a esclarecer otra fuente parcial que probablemente influyó en el proceso creador del autor. Su propio cuento; "Ella", constituye sin duda el precursor más importante de la no- 
vela de Rojas González. Pero más significativo es el juicio general que como novela La negra Angustias demuestra su propia individualidad. Su valor literario se mantiene firme o disminuye a base de sus aciertos literarios inherentes o sus propias deficiencias. Y la protagonista Angustias, a pesar de tener parentesco con una persona real, un personaje de la novela venezolana, y una figura dibujada por la pluma del mismo Francisco Rojas González, es fundamentalmente la criatura de la inspiración del autor. Su manera de ser se define dentro del marco de esta novela, con identidad y psicología determinadas únicamente por Rojas González en la obra de ficción que él creó.

Sus mejores cuentos, del mismo modo, ya sea que se hayan originado en algún encuentro accidental o en una expedición etnológica, o que fueran sugeridos por la historia de México o por alguna obra de otro autor, han sido forjados en creaciones independientes. Merecen por ello ser juzgados a base de sus propios valores.

La capacidad creadora y la peculiaridad del autor quedan establecidas. Arrancan directamente de la realidad circundante, y corresponden a su ideología literaria: que el papel de la literatura es el de reflejar la vida real, los problemas actuales. Su concepción humanista se parece a la que señaló William Faulkner, en su discurso al aceptar el Premio Nobel en I950:

El deber del poeta, del artista, es escribir de estas cosas. Es su privilegio ayudar al hombre a perdurar, elevando su corazón, recordándole el valor y el honor y la esperanza y el orgullo y la compasión y la piedad y el sacrificio que han constituido las glorias de su pasado.

La voz del poeta no ha ser tan sólo la memoria del hombre; puede ser uno de los puntales, los pilares, que le ayuden a perdurar y a prevalecer. ${ }^{17}$

A base de tal filosofía Francisco Rojas González aportó su contribución literaria a la cultura de su país, a medida que se desarrollaban las etapas fecundas de la Revolución Mexicana.

JOSEPH SOMMERS

University of $W$ asbington

17 Según el New York Times, 7 de julio, 1962, p. 6. Traducido por J. Sommers. 
